\title{
Accuracy of universal polymerase chain reaction (PCR) for detection of bacterial meningitis among suspected patients
}

\author{
Ali Reza Moayedi ${ }^{1}$, Abdolazim Nejatizadeh ${ }^{2}$, Maryam Mohammadian ${ }^{3}$, Mohammad Bagher Rahmati ${ }^{4}$, Vahideh \\ Namardizadeh $^{5}$
}

1 M.D., Assistant Professor, Department of Pediatric Neurology, Faculty of Medicine, Clinical Research Development Center of Children Hospital, Hormozgan University of Medical Sciences, Bandar Abbas , Iran

${ }^{2}$ Ph.D. of Genetics, Associate Professor, Department of Genetics, Faculty of Medicine, Hormozgan University of Medical Sciences, Bandar Abbas, Iran

${ }^{3}$ M.D., Pediatric Resident, Department of Pediatrics, Faculty of Medicine, Clinical Research Development Center of Children Hospital, Hormozgan University of Medical Sciences, Bandar Abbas , Iran

${ }^{4}$ M.D., Assistant Professor, Department of Pediatric Infectious Diseases, Faculty of Medicine, Infectious and tropical diseases research center, Hormozgan University of Medical Sciences, Bandar Abbas, Iran

${ }^{5}$ B.Sc., Department of Genetics, Faculty of Medicine, Khalije-Fars Molecular Medicine Research Center, Hormozgan University of Medical Sciences, Bandar Abbas, Iran

\section{Type of article: Original}

\begin{abstract}
Introduction: Central nervous system (CNS) infections are life-threatening diseases caused by viral, bacterial, parasitic and fungal microorganisms. The aim of this study was to determine the accuracy of universal polymerase chain reaction (PCR) for the detection of bacterial meningitis among patients who were referred to Koodakan Hospital in Bandar Abbas because they were suspected of having the disease.

Methods: This study was conducted in 2013 on the patients who were admitted to Bandar Abbas' Koodakan Hospital because they were suspected of having meningitis. A questionnaire, including demographic data, was completed for each patient. Universal PCR, Cerebrospinal fluid (CSF) analysis, and gram staining and cultures were done for all the patients. The data were analyzed using SPSS software.

Results: Among the 100 patients studied 59 (59\%) were male and $41(41 \%)$ were female. No patient in our study had a positive smear and culture for meningitis. Among the patients with negative smears and cultures six $(6 \%)$ had positive universal PCR, and 94 (94\%) had negative universal PCR. Based on these results, PCR had 95\% specificity and $100 \%$ negative predictive value for the prediction of meningitis. In 30 patients (30\%), the biochemical analysis of CSF were in favor of meningitis. Among the 30 patients, six patients (20\%) had positive universal PCR and 24 patients $(80 \%)$ had negative universal PCR.

Conclusion: Based on our results, the universal PCR test is useful in the diagnosis of bacterial meningitis in children. We recommend using it in combination with other tests, such as CSF analysis, for diagnosis of bacterial meningitis.
\end{abstract}

Keywords: meningitis, universal PCR, gram stain and culture

\section{Introduction}

Infections of the central nervous system (CNS) are life-threatening diseases caused by viral, bacterial, parasitic, and fungal microorganisms (1-4). In spite of advances in the diagnosis and management of acute bacterial meningitis, it is still a life-threatening condition. However, with proper antibiotic therapy and supportive care, the mortality is lower than $10 \%(5,6)$. The symptoms of CNS infections vary among different age groups. Therefore, fast and accurate diagnostic tests are very important for the rational use of antibiotics and for lowering the treatment costs (7-

\section{Corresponding author:}

Dr. Maryam Mohammadian. M.D., Department of pediatrics, Faculty of medicine, Hormozgan University of Medical Tel: +98.9171975498, E-mail: mahdi4957@gmail.com

Received: April 12, 2015, Accepted: August 23, 2015, Published: December 2015

iThenticate screening: August 17, 2015, English editing: September 27, 2015, Quality control: October 01, 2015

(c) 2015 The Authors. This is an open access article under the terms of the Creative Commons Attribution-NonCommercialNoDerivs License, which permits use and distribution in any medium, provided the original work is properly cited, the use is non-commercial and no modifications or adaptations are made. 
11). The usual diagnostic method for meningitis is gram staining and culture, which is dependent on previous use of antibiotics by the patient and is unable to fully differentiate between viral and bacterial infections. This method has a high rate of false negatives, which causes controversy concerning the selection and duration of appropriate treatment. Antibiotic therapy does not affect pleocytosis with neutrophil dominancy, protein level, or Cerebrospinal fluid (CSF) glucose level (11). Therefore, the diagnosis of bacterial meningitis can be made even when the culture is negative by this method, because these changes are not affected by antibiotic therapy during the first days after treatment. In this situation, molecular assessment can be helpful. Patients are very frequently diagnosed with CNS infection and negative CSF culture. The general objective of the study was to determine the accuracy of universal polymerase chain reaction (PCR) for the detection of bacterial meningitis among patients who were referred to Koodakan Hospital in Bandar Abbas because they were suspected of having the disease. The specific objectives of the study were to compare the results of the PCR test with the results of gram staining and culture for the detection of bacterial meningitis among patients suspected of having the disease; and to compare the results of the PCR test with CSF fluid analysis for the detection of bacterial meningitis among patients suspected of having the disease

\section{Material and Methods}

\subsection{Study setting and ethics}

This study was conducted in 2013 on the patients who were admitted to Bandar Abbas Koodakan Hospital because they were suspected of having meningitis. The study was approved by the Ethics Committee at Hormozgan University of Medical Sciences. All of the patients' data were kept confidential.

\subsection{Measurement tools}

A questionnaire that included demographic data was completed for each patient. Sample volumes of 500-1000 ml of the CSF samples were kept in in sterile conditions at $-80{ }^{\circ} \mathrm{C}$ for the next PCR test. Also, the samples were sent for gram staining and culture. For DNA extraction, $500 \mu \mathrm{l}$ of CSF were placed in a microtube, and gene extraction was done with a DNA minikit (Kimia Co.). The extracted solution was kept at $-20{ }^{\circ} \mathrm{C}$. The supernatant DNA of each microtube was measured by a Nano Drop machine by comparing the absorbance at wavelengths of 260 and $280 \mathrm{~nm}$. A $10^{8}$ concentrations of E. coli and acintrobacter species were prepared using $0.5 \mathrm{Mc}$ Farlen standard tube and DNA contents were used as pattern in PCR process. The sequences of the primers were: U1(F):5 CCAGCAGCCGCGGTA ATACG-3` and U2(R) :5`-ATCGG(C/A)TACCTTGTTACGACTTC-3`. The PCR reaction was conducted by mixing $2 \mu \mathrm{L}$ of extracted DNA, $1 \mu \mathrm{L}$ of forward and reverse primer, $8.5 \mu \mathrm{L}$ of sterile water, and $12.5 \mu \mathrm{L}$ of master mix. All of the products were purchased from Gen-Fan-Avaran Company. The PCR reaction was conducted using a thermocycler device (SENSOQUEST). The thermal cycle for the PCR reaction was $1 \mathrm{~min}$ at $95{ }^{\circ} \mathrm{C}$, then 25 cycles of 20 seconds each at $95{ }^{\circ} \mathrm{C}, 1 \mathrm{~min}$ at $63{ }^{\circ} \mathrm{C}, 1 \mathrm{~min}$ at $72{ }^{\circ} \mathrm{C}$, and $5 \mathrm{~min}$ at $72{ }^{\circ} \mathrm{C}$. The PCR products were detected using 1\% agar gel and UV transluminator device. Then, the molecular weight of the proliferated segments were measured and found to be about 1500 base pairs.

\subsection{Statistical analysis}

SPSS version 16 software was used for the statistical analysis and calculation of specificity and sensitivity of the tests. Chi-squared test and the independent samples t-test were used for data analysis.

\section{Results}

\subsection{Demographic information}

Among 100 patients studied, 59 (59\%) were male and 41 (41\%) were female. The ages of the participants ranged from 2 days to 11 years, and their mean age was 19.17 months. Among the patients 71 (71\%) were less than 18 months old, $22(22 \%)$ were 1.5 to 6 years old, and $7(7 \%)$ were 6 to 12 years old.

\subsection{Comparison of PCR results with gram staining and culture results}

No patient in our study had a positive smear and culture for meningitis. Among the patients with negative smears and cultures, $6(6 \%)$ had positive universal PCR and $94(94 \%)$ had negative universal PCR. Based on these results, PCR had $95 \%$ specificity and 100\% negative predictive value for the prediction of meningitis.

\subsection{Comparison of PCR results with CSF analysis results}

Analytical sensitivity of the methods was determined with two specific species, i.e., E. coli and acintrobacter, with concentrations of $10^{8}$ colonies per milliliter of CSF. Among the 100 patients studied, none had a positive gram staining or culture. PCR was positive for $6(6 \%)$ patients. In 30 patients $(30 \%)$, the biochemical analyses of CSF 
were in favor of meningitis. Among them $6(20 \%)$ patients had positive universal PCR and $24(80 \%)$ had negative universal PCR.

\section{Discussion}

Early diagnosis and treatment of meningitis is vital, and research is ongoing to identify accurate methods for the diagnosis of meningitis. Among the efforts to meet this goal, different PCR-based methods have been designed (12). Simple PCR methods are specific only for detection of a single specific antigen of a single specific microorganism and therefore cannot be used in laboratory. Also, some PCR methods are complex and costly, so they are not used in clinical laboratories. Designing methods based on health issues and available equipment can be helpful. Some molecular methods have been designed based on universal primers. In this study, we used conserved primers of the 16 srDNA gene, which is found in the genome of all bacteria (13). Detection of specific species of bacteria is of no help to physicians at the beginning of the disease. Physicians are able to detect a wide range of bacteria without using complex devices, and they easily can distinguish between bacterial and non-bacterial meningitis.

\subsection{Demographic information}

The mean age of the participants in this study was about 19 months, and a large percentage of the participants were less than 6 years old. Based on the patients' ages, different microorganisms can cause meningitis. Therefore, the results of our study cannot be applied for different age groups.

\subsection{Comparison of PCR results with gram staining and culture results}

Few gram staining and culture results are positive in our Center. In this study, we had no positive smear and culture tests. Therefore, this is an important limitation for interpretation of the smear and culture results for diagnosis of meningitis. Using universal PCR, we diagnosed six cases of meningitis. Therefore, considering the limitation of gram staining and culture in this study, using universal PCR is very helpful to increase the probability of correctly diagnosing bacterial meningitis. Also, other studies have reported that PCR and staining are highly accurate for the detection of bacterial meningitis (14).

\subsection{Comparison of PCR results with CSF analysis results}

Based on our results, all universal PCR positive cases of meningitis can be diagnosed by CSF analysis. Other researchers have confirmed that CSF analysis is a strong tool for the detection of bacterial meningitis and that it can be used to diagnose meningitis (15). However, we recommend using universal PCR in combination with CSF analysis for more accurate diagnoses.

\section{Conclusions}

Based on our results, the universal PCR test is useful in the diagnosis of bacterial meningitis in children. We recommend using it in combination with other tests, such as CSF analysis, for the diagnosis of bacterial meningitis. Future research should focus on the accuracy of the combination of these tests in diagnosing bacterial meningitis.

\section{Acknowledgments:}

The paper is extracted from the results of thesis done by Dr. Maryam Mohammadian. The authors thank the staff members at the Clinical Research Development Center of Children Hospital, Hormozgan University of Medical Sciences in Bandar Abbas who provided help and support in the preparation of this paper.

\section{Conflict of Interest:}

There is no conflict of interest to be declared.

\section{Authors' contributions:}

All authors contributed to this project and article equally. All authors read and approved the final manuscript.

\section{References}

1) Adeyemi B, Ross A. Profile and mortality outcome of patients admitted with cryptococcal meningitis to an urban district hospital in KwaZulu-Natal, South Africa. J Int AIDS Soc. 2014;17(4 Suppl 3):19623. doi: 10.7448/IAS.17.4.19623. PMID: 25394127

2) Wall EC, Cartwright K, Scarborough M, Ajdukiewicz KM, Goodson P, Mwambene J, et al. High mortality amongst adolescents and adults with bacterial meningitis in sub-Saharan Africa: an analysis of 715 cases from Malawi. PLoS One. 2013;8(7):e69783. doi: 10.1371/journal.pone.0069783. PMID: 23894538 
3) Khowaja AR, Mohiuddin S, Cohen AL, Khalid A, Mehmood U, Naqvi F, et al. Mortality and neurodevelopmental outcomes of acute bacterial meningitis in children aged $<5$ years in Pakistan. J Pediatr. 2013;163(1 Suppl):S86-S91 e1. doi: 10.1016/j.jpeds.2013.03.035. PMID: 23773600

4) Salekeen S, Mahmood K, Naqvi IH, Baig MY, Akhter ST, Abbasi A. Clinical course, complications and predictors of mortality in patients with tuberculous meningitis--an experience of fifty two cases at Civil Hospital Karachi, Pakistan. J Pak Med Assoc. 2013;63(5):563-7. PMID: 23757980

5) Namani S, Milenkovic Z, Kuchar E, Koci R, Mehmeti M. Mortality from bacterial meningitis in children in Kosovo. J Child Neurol. 2012;27(1):46-50. doi: 10.1177/0883073811413280. PMID: 21765151

6) Roed C, Engsig FN, Omland LH, Skinhoj P, Obel N. Long-term mortality in children diagnosed with Haemophilus influenzae meningitis: a Danish nationwide cohort study. Pediatr Infect Dis J. 2011;30(8):e147-54. doi: 10.1097/INF.0b013e3182191a63. PMID: 21487329

7) Shirani K, Talaei Z, Yaran M, Ataei B, Mehrabi-Koushki A, Khorvash F. Diagnosed tuberculous meningitis using cerebrospinal fluid polymerase chain reaction in patients hospitalized with the diagnosis of meningitis in referral hospitals in Isfahan. J Res Med Sci. 2015;20(3):224-7. PMID: 26109966

8) Philip N, William T, William DV. Diagnosis of tuberculous meningitis: challenges and promises. Malays J Pathol. 2015;37(1):1-9. PMID: 25890607

9) Aneja S. Acute bacterial meningitis--early diagnosis and complications. Indian J Pediatr. 2015;82(4):303-5. doi: 10.1007/s12098-015-1689-3. PMID: 25683076

10) Turel O, Bakir M. Is the diagnosis and treatment of childhood acute bacterial meningitis in Turkey evidence-based? Turk J Med Sci. 2014;44(5):764-8. PMID: 25539542

11) Manning L, Laman M, Mare T, Hwaiwhanje I, Siba P, Davis TM. Accuracy of cerebrospinal leucocyte count, protein and culture for the diagnosis of acute bacterial meningitis: a comparative study using Bayesian latent class analysis. Trop Med Int Health. 2014;19(12):1520-4. doi: 10.1111/tmi.12400. PMID: 25315120

12) Welinder-Olsson C, Dotevall L, Hogevik H, Jungnelius R, Trollfors B, Wahl M, et al. Comparison of broad-range bacterial PCR and culture of cerebrospinal fluid for diagnosis of community-acquired bacterial meningitis. Clin Microbiol Infect. 2007;13(9):879-86. doi: 10.1111/j.1469-0691.2007.01756.x. PMID: 17608746

13) Radstrom P, Backman A, Qian N, Kragsbjerg P, Pahlson C, Olcen P. Detection of bacterial DNA in cerebrospinal fluid by an assay for simultaneous detection of Neisseria meningitidis, Haemophilus influenzae, and streptococci using a seminested PCR strategy. J Clin Microbiol. 1994;32(11):2738-44. PMID: 7852565

14) Wu HM, Cordeiro SM, Harcourt BH, Carvalho M, Azevedo J, Oliveira TQ, et al. Accuracy of real-time PCR, Gram stain and culture for Streptococcus pneumoniae, Neisseria meningitidis and Haemophilus influenzae meningitis diagnosis. BMC Infect Dis. 2013;13:26. doi: 10.1186/1471-2334-13-26. PMID: 23339355

15) Margall Coscojuela N, Majo Moreno M, Latorre Otin C, Fontanals Amyerich D, Dominguez Garcia A, Prats Pastor G. Use of universal PCR on cerebrospinal fluid to diagnose bacterial meningitis in culturenegative patients. Eur J Clin Microbiol Infect Dis. 2002;21(1):67-9. PMID: 11913508 